\title{
Endovascular Treatment of Anterior Communicating Artery Aneurysms: A Systematic Review and Meta-Analysis
}

\author{
S. Fang, W. Brinjikji, M.H. Murad, D.F. Kallmes, H.J. Cloft, and G. Lanzino
}

\begin{abstract}
BACKGROUND AND PURPOSE: Endovascular therapy has become an acceptable alternative to traditional clipping for the management of intracranial aneurysms. However, a limited number of studies have examined outcomes and complications specific to embolization of anterior communicating artery aneurysms.
\end{abstract}

MATERIALS AND METHODS: A systematic review of the literature was conducted with the use of multiple data bases to identify reports on endovascular treatment of anterior communicating artery aneurysms between 1994 and 2012. Angiographic results, clinical outcomes, and complication rates were pooled across studies by using random-effects meta-analysis with subgroup analysis of outcomes by rupture status and time trend stratification.

RESULTS: Fourteen studies, consisting of 1552 treated anterior communicating artery aneurysms, were included in this meta-analysis. The rate of immediate and long-term complete and near-complete angiographic occlusion was $88 \%(95 \% \mathrm{Cl}=81-93 \%)$ and $85 \%(95 \% \mathrm{Cl}=$ $78-90 \%)$, respectively. Intraprocedural rupture rate was $4 \%(95 \% \mathrm{Cl}=3-6 \%)$. The re-bleeding rate was $2 \%(95 \% \mathrm{Cl}=1-4 \%)$ and the retreatment rate was $7 \%(95 \% \mathrm{Cl}=5-12 \%)$. Morbidity or mortality caused by perioperative stroke occurred at a $3 \%(95 \% \mathrm{Cl}=2-6 \%)$ rate. Overall procedure-related morbidity and mortality were $6 \%(95 \% \mathrm{Cl}=4-8 \%)$ and $3 \%(95 \% \mathrm{Cl}=2-4 \%)$, respectively. Outcomes did not differ between ruptured and unruptured aneurysms, nor did outcomes change over time, though these latter subanalyses were relatively underpowered.

CONCLUSIONS: Endovascular therapy for anterior communicating artery aneurysms is associated with a high rate of complete angiographic occlusion. However, the procedure-related permanent morbidity and mortality are not negligible for aneurysms in this location.

ABBREVIATION: AcomA = anterior communicating artery; ISAT = International Subarachnoid Aneurysm Trial; CARAT = Cerebral Aneurysm Rerupture After Treatment

$\mathbf{T}$ he anterior communicating artery (AcomA) is the most common location for intracranial aneurysms in most series, and rupture of aneurysms in this location accounts for approximately $40 \%$ of aneurysmal subarachnoid hemorrhages in adults. ${ }^{1-5}$ Aneurysms of the AcomA can be technically challenging from a surgical perspective because of complex regional flow dynamics, frequent anatomic variations, variable geometry, and the presence of critical perforators. ${ }^{1,6-10}$ In the past 2 decades, the inherently less

Received May 15, 2013; accepted after revision October 2.

From Mayo Medical School (S.F.), Department of Radiology (W.B., D.F.K., H.J.C.), Division of Preventive Medicine (M.H.M.), and Department of Neurologic Surgery (G.L.), Mayo Clinic, Rochester, Minnesota.

Please address correspondence to Giuseppe Lanzino, MD, Department of Neurological Surgery, Mayo Clinic, 200 First St SW, Rochester, MN 55905; e-mail: lanzino.giuseppe@mayo.edu

三 Indicates article with supplemental on-line tables.

Evidence-Based Medicine Level 1.

http://dx.doi.org/10.3174/ajnr.A3802 invasive endovascular approach has emerged as a feasible and acceptable treatment option for AcomA aneurysms. ${ }^{11-14}$ Continual advancements in endovascular technique and adjuvant devices have led to an enlarging proportion of patients with AcomA aneurysms who are successfully treated with coil embolization. ${ }^{10,11,15,16}$ A limited number of case series have detailed the clinical outcomes, angiographic results, and procedure-related complications specific for endovascular treatment in this location. ${ }^{10-13,15-24}$ We performed a systematic review of the published literature to better define safety and efficacy profiles for coil embolization of AcomA aneurysms beyond single-center experiences.

\section{MATERIALS AND METHODS Systematic Literature Search}

We performed a comprehensive review of the literature between January 1994 to December 2012 through the use of the key words "anterior communicating artery," "intracranial aneurysm," "en- 
Table 1: Studies included in meta-analysis

\begin{tabular}{llcccc}
\multicolumn{1}{c}{ Author (year) } & Study Design & $\begin{array}{c}\text { No. of Patients with } \\
\text { AcomA Aneurysms }\end{array}$ & $\begin{array}{c}\text { AcomA Aneurysms } \\
\text { Treated }\end{array}$ & $\begin{array}{c}\text { Patients with Ruptured } \\
\text { AcomA Aneurysms }\end{array}$ & $\begin{array}{c}\text { Patients with Unruptured } \\
\text { AcomA Aneurysms }\end{array}$ \\
\hline Birknes et al (2006) & Retrospective & 123 & 123 & 113 & 10 \\
Cherian et al (2001) & Prospective & 103 & 103 & 103 & 0 \\
Choi et al (2011) & Retrospective & 45 & 45 & 45 & 0 \\
Elias et al (2003) & Prospective & 30 & 30 & 30 & 0 \\
Finitsis et al (2010) & Prospective & 280 & 281 & 239 & 72 \\
Guglielmi et al (2009) & Retrospective & 306 & 306 & 20 & 0 \\
Huang et al (2011) & Retrospective & 20 & 20 & - & - \\
Johnson et al (2012) & Retrospective & 64 & 64 & 20 & 0 \\
Leclerc et al (2002) & Prospective & 20 & 20 & 30 & 6 \\
Moret et al (1996) & Prospective & 36 & 36 & 36 & 1 \\
Proust et al (2003) & Prospective & 37 & 37 & 43 & 70 \\
Raslan et al (2011) & Retrospective & 44 & 44 & 277 & 7 \\
Schuette et al (2011) & Retrospective & 347 & 347 & 96 & 89 \\
Songsaeng et al (2010) & Retrospective & 96 & & \\
\hline
\end{tabular}

Note:-Studies are from References $10-13$ and 15-24. AcomA indicates anterior communicating artery.

dovascular," "coil," and "embolization" in the PubMed, Ovid MEDLINE, Ovid EMBASE, Scopus, and Web of Science data bases. Studies reporting on the endovascular treatment of AcomA aneurysms were selected. All case reports, reviews, and articles not published in English were excluded. The search strategy for the electronic data bases was developed and conducted by a reference librarian with expertise in systematic reviews.

Identified studies were reviewed for inclusion in the metaanalysis on the basis of these criteria: 1) studies reporting on endovascular treatment of consecutive series of AcomA intracranial aneurysms comprising $\geq 20$ patients, 2 ) studies providing rates of aneurysmal occlusion and data on intra- and postoperative complications, and 3) studies reporting the rupture status of treated aneurysms. For multiple series from the same institution or authors, only the most recent (usually larger) series was included to avoid including the same patients in the analysis.

For each included study, information was extracted with regard to aneurysm rupture status, immediate angiographic outcomes, long-term angiographic outcomes, and retreatment rate. Long-term angiographic outcomes were only included for those studies with 6 months or more of angiographic follow-up. Complete occlusion was defined as absence of angiographic filling in aneurysm neck or sac, and near-complete occlusion was defined as small residual neck filling without any filling of the sac. For procedure-related complications, we extracted information regarding intraoperative rupture, vasospasm, perioperative thromboembolic complications resulting in morbidity and mortality, re-hemorrhage, and procedure-related mortality and permanent morbidity. Procedure-related mortality and morbidity were defined as permanent morbidity and mortality resulting from intraoperative rupture, cerebral ischemia, new neurologic deficits, aneurysmal re-bleeding, sepsis, and myocardial infarction during the perioperative period.

\section{Statistical Analysis}

We estimated the cumulative incidence (event rate at the end of study follow-up) and 95\% CI for every outcome. Event rates were pooled across studies by means of random-effects meta-analysis. $^{25}$ We considered outcomes of ruptured and unruptured AcomA aneurysms separately, as well as a combined outcome. We also performed subgroup analysis comparing outcomes of studies published from the years 2007-2012 and those published before 2007. Interaction of covariates with the log of event rate was performed as described by Altman. ${ }^{26}$ The $I^{2}$ statistic was used to evaluate the extent of heterogeneity across studies and represents the proportion of heterogeneity in study results that is not attributable to chance or random error. ${ }^{27}$ Values of $<25 \%$, 25-50\%, and $>50 \%$ are consistent with small, moderate, and substantial heterogeneity, respectively. We conducted Begg and Mazumdar rank correlation to evaluate publication bias. All statistical analyses were performed with the use of Comprehensive Meta-Analysis Version 2.0 (www.meta-analysis.com).

\section{RESULTS}

\section{Study Selection}

Data base search led to the retrieval of 488 articles, 14 of which fulfilled the criteria for inclusion. These included 8 retrospective consecutive series and 6 prospective studies. A summary of the studies included in this meta-analysis is provided in Table 1. Five of these studies included outcomes of patients with ruptured aneurysms only, whereas 9 studies included outcomes of patients with both ruptured and unruptured AcomA aneurysms. Information on angiographic outcomes, perioperative complications, and procedure-related morbidity and mortality was not consistently provided in every study. Furthermore, not all studies that included both ruptured and unruptured AcomA aneurysms described stratified outcomes with regard to rupture status. In total, this meta-analysis included 1551 patients, with 1552 treated AcomA aneurysms. In the 13 articles reporting numbers of patients presenting with ruptured or unruptured status, there was a total of 1488 patients with AcomA aneurysms. These consisted of 1199 patients presenting with ruptured aneurysms and 289 patients presenting with unruptured aneurysms.

\section{Study Outcomes}

Immediate and Long-Term Angiographic Outcomes. The overall rate of complete and near-complete occlusion (>95\%) immediately after procedure was $88 \%(95 \% \mathrm{CI}=81-93 \%)$. At follow-up, at least 6 months after the procedure, the complete and nearcomplete occlusion was $85 \%$ (95\% CI $=78-90 \%)$. Occlusion rates for ruptured and unruptured aneurysms were similar for 


\begin{tabular}{|c|c|c|c|c|}
\hline Outcome & $\begin{array}{l}\text { No. of } \\
\text { Studies }\end{array}$ & $\begin{array}{l}\text { Raw No. of Events in } \\
\text { All Aneurysms }{ }^{\text {a }}\end{array}$ & $\begin{array}{c}\text { Meta-Analysis } \\
\text { Percentage }(95 \% \mathrm{CI})\end{array}$ & $I^{2}$ \\
\hline Intraoperative rupture & 11 & $57 / 1387$ & $4 \%(3-6 \%)$ & 0 \\
\hline Vasospasm & 6 & 182/1091 & $13 \%(5-28 \%)$ & 95 \\
\hline Re-bleeding event & 11 & $16 / 1065$ & $2 \%(1-4 \%)$ & 0 \\
\hline Aneurysm retreatment & 10 & $73 / 777$ & $7 \%(5-12 \%)$ & 60 \\
\hline Morbidity or mortality due to stroke $<30$ days & 10 & $21 / 771$ & $3 \%(2-6 \%)$ & 32 \\
\hline Permanent procedure-related morbidity & 11 & $53 / 1077$ & $6 \%(4-8 \%)$ & 47 \\
\hline Procedure-related mortality & 11 & $25 / 1077$ & $3 \%(2-4 \%)$ & 15 \\
\hline
\end{tabular}

a Discordances between the raw event percentages and the percentages calculated from the meta-analysis are caused by greater weights assigned to outcomes of studies with larger sample sizes.

both the immediate $(P=.13)$ and long-term follow-up $(P=.39)$. The overall rate of retreatment as the result of re-bleeding, recanalization, or aneurysmal growth was 7\% (95\% CI $=5-12 \%)$. Ruptured and unruptured aneurysms did not show significantly different rates of retreatment after the procedure $(P=.61)$. These results are shown in On-line Table 1.

Procedure-Related-Complications. The intraprocedural rupture rate in all aneurysms was $4 \%(95 \% \mathrm{CI}=3-6 \%)$. The rupture rate was not significantly different between ruptured and unruptured aneurysms $(P=.87)$. Vasospasm was reported at an overall rate of $13 \%(95 \% \mathrm{CI}=5-28 \%)$. The rate of vasospasm was $11 \%(95 \%$ $\mathrm{CI}=3-30 \%)$ in ruptured aneurysms and $1 \%(95 \% \mathrm{CI}=3-30 \%)$ in unruptured aneurysms. Aneurysmal re-bleeding occurred in $2 \%$ of patients $(95 \% \mathrm{CI}=1-4 \%$ ), with similar rates of postprocedure bleeding in ruptured and unruptured aneurysms $(P=$ $.50)$. These results are shown in Table 2. Outcome event rates from overall and ruptured/unruptured aneurysms are compared in On-line Table 2.

Morbidity and Mortality From Endovascular Treatment. Overall procedure-related permanent morbidity and mortality was $6 \%$ $(95 \% \mathrm{CI}=4-8 \%)$ and $3 \%(95 \% \mathrm{CI}=2-4 \%)$, respectively. Permanent morbidity was $7 \%(95 \% \mathrm{CI}=4-12 \%)$ for ruptured aneurysms and $8 \%$ (95\% CI $=3-20 \%)$ for unruptured aneurysms $(P=.90)$. Mortality as the result of the procedure was $4 \%(95 \%$ $\mathrm{CI}=3-7 \%)$ in ruptured aneurysms and $2 \%(95 \% \mathrm{CI}=1-9 \%)$ for unruptured aneurysms $(P=.40)$. Among ruptured aneurysms, the rate of death attributed to the presenting SAH was 7\% (95\% $\mathrm{CI}=4-13 \%)$. No difference was observed in the morbidity or mortality rates as the result of perioperative stroke between ruptured and unruptured aneurysms $(P=.49)$.

Time-Trend Analysis of Angiographic Results and Complication Rates. We analyzed the outcomes for studies published before 2007 as compared with studies published between 2007 and 2012. The rate of aneurysm occlusion and procedure-related complications did not differ significantly over time. The results are shown in On-line Table 3.

Heterogeneity and Publication Bias. Analysis of the statistical heterogeneity across the studies included in this meta-analysis was low to moderate for most outcomes. Outcomes associated with significant heterogeneity $\left(I^{2}>50 \%\right)$ were the angiographic outcomes immediately after surgery $\left(I^{2}=82\right)$ and in long-term follow-up $\left(I^{2}=69\right)$, vasospasm $\left(I^{2}=95\right)$, and aneurysm retreatment $\left(I^{2}=60\right)$. Information provided in the studies was not sufficient for further analysis of possible causes for the observed dif- ferences in patient populations or in treatments, including any effect of subgroup analysis on heterogeneity.

The results of the Begg and Mazumdar rank correlation test do not suggest publication bias $(P>.05)$ for study outcomes with minimal or moderate heterogeneity $\left(I^{2}<50 \%\right)$. For analyses associated with heterogeneity, evaluation of publication bias was not possible because statistical testing for funnel asymmetry assumes a fixed-effect model with no heterogeneity.

\section{DISCUSSION}

In this meta-analysis, we combined data from 14 studies to analyze the representative outcomes for angiographic occlusion, procedure-related complications, and morbidity as well as mortality associated with endovascular treatment of AcomA aneurysms. Our results demonstrated that AcomA aneurysms can be successfully treated with endovascular embolization and maintain a high rate of complete or near-complete occlusion at follow-up. However, complications associated with coil embolization of AcomA aneurysms are not negligible, with a permanent morbidity rate of $6 \%$ and mortality rate of $3 \%$.

Since the introduction of Guglielmi Detachable Coils in 1991, endovascular technique has dramatically changed the management of these aneurysms and established coiling as an acceptable alternative option to traditional clip ligation. ${ }^{13,18,28,29}$ Large, randomized trials such as the International Subarachnoid Aneurysm Trial (ISAT) and the Barrow Ruptured Aneurysm Trial have shown that patients with ruptured aneurysms have significant advantages in disability independent survival and functional outcome when compared with those treated surgically. ${ }^{30,31}$ However, one of the major limitations of endovascular treatment continues to be the risk of postprocedure re-bleeding. Data from ISAT and the Cerebral Aneurysm Rerupture After Treatment (CARAT) studies show significantly higher risks of re-bleeding after endovascular treatment as compared with surgical therapy. ${ }^{4,32}$ In our meta-analysis, we found that the rate of periprocedural re-bleeding for AcomA aneurysms with endovascular retreatment was $2 \%$, which is consistent with rates reported in CARAT and ISAT. However, recurrence or rupture of aneurysms after the initial treatment requiring retreatment by secondary coiling or clipping occurred in $7 \%$ of cases.

With the advances made in endovascular technology in recent years, the characteristics of complicated AcomA aneurysms that previously precluded treatment by coiling are increasingly challenged. The inherent small diameter of the AcomA from which the aneurysm rises as well as the propensity for AcomA aneurysms to be small in size or wide-neck are the features that can make 
endovascular treatment difficult. ${ }^{11,13,17}$ Since the mid-1990s, advances in technology such as $3 \mathrm{D}$ rotational angiography and newer microguidewire/catheters, in combination with adjunctive devices such as balloon-assisted or stent-assisted coiling, have revolutionized treatment of aneurysms once deemed unfeasible to coil. Newer studies are beginning to examine the effects of these adjunctive devices on long-term angiographic stability and complications and recurrence rates associated with endovascular treatment; however, this is not yet well characterized for coiling therapy in AcomA aneurysms. ${ }^{10,20,23}$

To determine any effect of advancements in technology and operator experience on the safety and efficacy of AcomA embolization, we looked at the angiographic and complication outcomes of patients in studies published before 2007 as compared with those published between 2007 and 2012. No statistically significant differences were found in our analysis of angiographic results or complications, which might be caused by underpowering. However, there was a trend suggesting decreased overall procedure-related permanent morbidity and mortality in the studies published from 2007-2012. This trend of decreased morbidity and mortality observed in patients with AcomA aneurysm over time is consistent with the finding that morbidity and mortality rates have increasingly been reduced across time among a sample of patients treated with endovascular coiling in the United States (Nationwide Inpatient Sample). ${ }^{28,33,34}$ These studies showed that morbidity rates decreased from $7.6-4.9 \%$ in the analysis of patients treated with endovascular therapy in 1996-2000 compared with 2001-2008. Mortality rates of overall patients treated with endovascular coiling decreased from $1.7 \%$ in $1996-2000$ to $0.6 \%$ in 2001-2008.

Across this time period stratification, our meta-analysis also showed that the overall aneurysm retreatment rate doubled from 5-10\% when comparing studies published before and after 2007; however, the trend toward an increase was not statistically significant. Given the consistently smaller number of studies included in the "before 2007" time period stratification group, along with nationally increased use of embolization therapy over time, this increased trend found in retreatment rate may reflect a larger and more representative sample size in the 2007-2012 stratification group. Alternatively, this trend may be a result of endovascular coil embolization applied to a subset of aneurysms that are not necessarily considered "ideal" for endovascular treatment due to higher risks of recanalization.

There are several limitations to this study. Because of the highly selected cases available for analysis, this systematic review does not provide information on the proportion of all AcomA aneurysms that met the criteria for endovascular treatment. Many published studies collected data retrospectively; therefore, stratification of outcomes by rupture status and other variables such as previous rupture and number or types of adjunctive devices used was not provided in every study. The studies that were performed prospectively were not randomized studies and did not include control groups. Many of the studies included in this meta-analysis ranged in sample size, and several of the studies did not provide complete follow-up data in terms of clinical outcome or angiographic results. The included studies covered consecutive patients over many years; however, the different time periods covered largely limited our ability to stratify and scrutinize outcomes over time. Further temporal stratification of outcomes may reveal variations in complication rates over time as a result of increased experience or improvements in technology.

An important limitation of this meta-analysis is the variability inherent in assessment of angiographic outcomes for endovascular treatment of aneurysms. Multiple studies have shown only "fair" interobserver and intra-observer agreement on interpretation of the completeness of occlusion after coiling, with improvement to "moderate" agreement with follow-up angiography. ${ }^{35,36}$ However, judgment and adjudicating aneurysms into a residual aneurysms category remain poor and can vary among observers to range from $20-60 \% .{ }^{36}$ The interobserver and intra-observer variability is inherent to the assessment scales used for extent of occlusion and can result in decreased variability in scales with fewer response options, though this can be less ideal for assessing effects of occlusion completeness on important outcomes such as recurrence or re-hemorrhage. ${ }^{35,37}$ Although we were unable to individually validate the extent of occlusion for each aneurysm, many studies used the Raymond-Roy classification system ${ }^{38}$ for categorization of angiographic outcomes, and we adhered to this scale as best we could, given the descriptors used in the methods for included studies. Despite this, caution is warranted when interpreting the results of this meta-analysis. It is important to consider the effects of the interobserver and intra-observer variability because the data used are gathered from case series from different institutions with the use of various technologies and equipment and conducted by specialists with ranging levels of experience and techniques.

\section{CONCLUSIONS}

The results of this meta-analysis suggest that the endovascular treatment of AcomA aneurysms is feasible and effective and can maintain high rates of complete and near-complete occlusion at long-term follow-up. However, the procedure-related morbidity and mortality associated with this treatment technique are not negligible and should be considered when deciding the best management approach to AcomA aneurysms.

\section{ACKNOWLEDGMENTS}

This study was supported by the Center for the Science of Health care Delivery and the Center for Translational Science Activities, Mayo Clinic, Rochester, Minnesota. The authors thank Sherry Kallies for assistance in editing and preparing the manuscript for submission.

Disclosures: David F. Kallmes—UNRELATED: Consultancy: General Electric, ev3, Codman, ${ }^{*}$ Comments: General consulting regarding planning and implementation of clinical trials; serving as investigator in ongoing trials; Grants/Grants Pending: Sequent, Codman, ev3, Benvenue, ${ }^{\star}$ MicroVention; Royalties: UVA Patent Foundation, Comments: License fees for spine fusion technology; Travel/Accommodations/ Meeting Expenses Unrelated to Activities Listed: MicroVention, ${ }^{\star}$ ev3*; Comments: Presentation at meetings. Harry J. Cloft_UNRELATED: Grants/Grants Pending: Cordis Endovascular, ${ }^{*}$ Comments: Site PI at enrolling site for SAPPHIRE (Stenting and Angioplasty with Protection in Patients and HIgh Risk for Endarterectomy) registry sponsored by Cordis Endovascular. Giuseppe Lanzino-UNRELATED: Consultancy: ev3/Covidien*; OTHER: Unrelated educational grants to the institution. 


\section{REFERENCES}

1. Hernesniemi J, Dashti R, Lehecka M, et al. Microneurosurgical management of anterior communicating artery aneurysms. Surg Neurol 2008;70:8-28

2. Kassell NF, Torner JC, Haley EC Jr, et al. The International Cooperative Study on the Timing of Aneurysm Surgery, part 1: overall management results. J Neurosurg 1990;73:18-36

3. Le Roux PD, Elliott JP, Downey L, et al. Improved outcome after rupture of anterior circulation aneurysms: a retrospective 10-year review of 224 good-grade patients. J Neurosurg 1995;83:394-402

4. Molyneux AJ, Kerr RS, Birks J, et al. Risk of recurrent subarachnoid haemorrhage, death, or dependence and standardised mortality ratios after clipping or coiling of an intracranial aneurysm in the International Subarachnoid Aneurysm Trial (ISAT): long-term follow-up. Lancet Neurol 2009;8:427-33

5. Brisman JL, Song JK, Newell DW. Cerebral aneurysms. N Engl J Med 2006;355:928-39

6. Riina HA, Lemole GM Jr, Spetzler RF. Anterior communicating artery aneurysms. Neurosurgery 2002;51:993-96

7. Nathal E, Yasui N, Sampei T, et al. Intraoperative anatomical studies in patients with aneurysms of the anterior communicating artery complex. J Neurosurg 1992;76:629-34

8. Kirgis HD, Fisher WL, Llewellyn RC, et al. Aneurysms of the anterior communicating artery and gross anomalies of the circle of Willis. J Neurosurg 1966;25:73-78

9. Sekhar LN, Natarajan SK, Britz GW, et al. Microsurgical management of anterior communicating artery aneurysms. Neurosurgery 2007;61(5 Suppl 2):273-90

10. Huang QH, Wu YF, Xu Y, et al. Vascular geometry change because of endovascular stent placement for anterior communicating artery aneurysms. AJNR Am J Neuroradiol 2011;32:1721-25

11. Moret J, Pierot L, Boulin A, et al. Endovascular treatment of anterior communicating artery aneurysms using Guglielmi detachable coils. Neuroradiology 1996;38:800-05

12. Birknes JK, Hwang SK, Pandey AS, et al. Feasibility and limitations of endovascular coil embolization of anterior communicating artery aneurysms: morphological considerations. Neurosurgery 2006; 59:43-52

13. Guglielmi G, Vinuela F, Duckwiler G, et al. Endovascular treatment of 306 anterior communicating artery aneurysms: overall, perioperative results. J Neurosurg 2009;110:874-79

14. Proust F, Martinaud O, Gerardin E, et al. Quality of life and brain damage after microsurgical clip occlusion or endovascular coil embolization for ruptured anterior communicating artery aneurysms: neuropsychological assessment. J Neurosurg 2009;110:19-29

15. Cherian MP, Pranesh MB, Mehta P, et al. Outcomes of endovascular coiling of anterior communicating artery aneurysms in the early post-rupture period: a prospective analysis. Neurol India 2001;59: $218-23$

16. Schuette AJ, Hui FK, Spiotta AM, et al. Endovascular therapy of very small aneurysms of the anterior communicating artery: five-fold increased incidence of rupture. Neurosurgery 2011;68:731-37

17. Choi JH, Kang MJ, Huh JT. Influence of clinical and anatomic features on treatment decisions for anterior communicating artery aneurysms. J Korean Neurosurg Soc 2011;50:81-88

18. Elias T, Ogungbo B, Connolly D, et al. Endovascular treatment of anterior communicating artery aneurysms: results of clinical and radiological outcome in Newcastle. Br J Neurosurg 2003;17:278-86

19. Finitsis S, Anxionnat R, Lebedinsky A, et al. Endovascular treatment of ACom intracranial aneurysms: report on series of 280 patients. Interv Neuroradiol 2010;16:7-16
20. Johnson AK, Munich SA, Heiferman DM, et al. Stent assisted embolization of 64 anterior communicating artery aneurysms. J Neurointerv Surg 2012;5:Suppl 3 iii62-iii65

21. Leclerc X, Navez JF, Gauvrit JY, et al. Aneurysms of the anterior communicating artery treated with Guglielmi detachable coils: follow-up with contrast-enhanced MR angiography. AJNR Am J Neuroradiol 2002;23:1121-27

22. Proust F, Debono B, Hannequin D, et al. Treatment of anterior communicating artery aneurysms: complementary aspects of microsurgical and endovascular procedures. J Neurosurg 2003;99:3-14

23. Raslan AM, Oztaskin M, Thompson EM, et al. Neuroform stentassisted embolization of incidental anterior communicating artery aneurysms: long-term clinical and angiographic follow-up. Neurosurgery 2011;69:27-37

24. Songsaeng D, Geibprasert S, Willinsky R, et al. Impact of anatomica variations of the circle of Willis on the incidence of aneurysms and their recurrence rate following endovascular treatment. Clin Radiol 2010;65:895-901

25. DerSimonian R, Laird N. Meta-analysis in clinical trials. Control Clin Trials 1986;7:177-88

26. Altman DG, Bland JM. Interaction revisited: the difference between two estimates. $B M J$ 2003;326:219

27. Higgins JP, Thompson SG, Deeks JJ, et al. Measuring inconsistency in meta-analyses. BMJ 2003;327:557-60

28. Brinjikji W, Rabinstein AA, Nasr DM, et al. Better outcomes with treatment by coiling relative to clipping of unruptured intracranial aneurysms in the United States, 2001-2008. AJNR Am J Neuroradiol 2011;32:1071-75

29. Cowan JA Jr, Ziewacz J, Dimick JB, et al. Use of endovascular coil embolization and surgical clip occlusion for cerebral artery aneurysms. J Neurosurg 2007;107:530-35

30. Molyneux A, Kerr R, Stratton I, et al. International Subarachnoid Aneurysm Trial (ISAT) of neurosurgical clipping versus endovascular coiling in 2143 patients with ruptured intracranial aneurysms: a randomized trial. J Stroke Cerebrovasc Dis 2002;11: 304-14

31. McDougall CG, Spetzler RF, Zabramski JM, et al. The Barrow Ruptured Aneurysm Trial. J Neurosurg 2012;116:135-44

32. Carat Investigators. Rates of delayed rebleeding from intracranial aneurysms are low after surgical and endovascular treatment. Stroke 2006;37:1437-42

33. Alshekhlee A, Mehta S, Edgell RC, et al. Hospital mortality and complications of electively clipped or coiled unruptured intracranial aneurysm. Stroke 2010;41:1471-76

34. Hoh BL, Rabinov JD, Pryor JC, et al. In-hospital morbidity and mortality after endovascular treatment of unruptured intracranial aneurysms in the United States, 1996-2000: effect of hospital and physician volume. AJNR Am J Neuroradiol 2003;24:1409-20

35. Cloft HJ, Kaufmann T, Kallmes DF. Observer agreement in the assessment of endovascular aneurysm therapy and aneurysm recurrence. AJNR Am J Neuroradiol 2007;28:497-500

36. Tollard E, Darsaut TE, Bing F, et al. Outcomes of endovascular treatments of aneurysms: observer variability and implications for interpreting case series and planning randomized trials. AJNR Am J Neuroradiol 2012;33:626-31

37. Raymond J, White PM, Molyneux AJ. Scales, agreement, outcome measures, and progress in aneurysm therapy. AJNR Am J Neuroradiol 2007;28:501-02

38. Raymond J, Guilbert F, Weill A, et al. Long-term angiographic recurrences after selective endovascular treatment of aneurysms with detachable coils. Stroke 2003;34:1398-403 